\title{
REVIEW
}

Open Access

\section{Muscle-strengthening activities and cancer incidence and mortality: a systematic review and meta-analysis of observational studies}

Wilson Nascimento ${ }^{1}$, Gerson Ferrari ${ }^{2}$, Camila Bertini Martins' ${ }^{1}$, Juan Pablo Rey-Lopez ${ }^{3,4}$, Mikel Izquierdo ${ }^{5}$, Dong Hoon Lee ${ }^{6}$, Edward L. Giovannucci, ${ }^{6,7,8}$ and Leandro F. M. Rezende ${ }^{1^{*}}$ (i)

\begin{abstract}
Background: Physical activity has been associated with reduced risk of seven types of cancer. It remains unclear, however, whether muscle-strengthening activities also reduce cancer incidence and mortality.

Methods: PubMed, Embase, Web of Science and Scopus were searched from inception to March 2020. Summary hazard ratio (HR) and 95\% confidence intervals (Cl) were estimated using random-effects models.

Results: Twelve studies (11 cohorts; 1 case-control), 6 to 25 years of follow-up, including 1,297,620 participants, 32, 196 cases and 31,939 deaths, met inclusion criteria. Muscle-strengthening activities were associated with a 26\% lower incidence of kidney cancer (HR for high vs low levels of muscle-strengthening activities: $0.74 ; 95 \% \mathrm{Cl} 0.56$ to $0.98 ; l^{2}$ 0\%; 2 studies), but not with incidence of other 12 types of cancer. Muscle-strengthening activities were associated with lower total cancer mortality: HRs for high vs low levels of muscle-strengthening activities was 0.87 (95\% Cl 0.73 to $1.02 ; P^{2} 58 \% ; 6$ studies); and HR for $\geq 2$ times/week vs $<2$ times/week of muscle-strengthening activities was 0.81 (95\% Cl 0.74 to $0.87 ; I^{2}$ 0\%; 4 studies). Regarding the weekly duration of muscle-strengthening activities, HR for total cancer mortality were 0.91 (95\% Cl 0.82 to 1.01; $\mathcal{L}^{2} 0 \% ; 2$ studies) for $1-59 \mathrm{~min} /$ week and 0.98 ( $95 \% \mathrm{Cl} 0.89$ to $1.07 ; I^{2}$ 0\%) for $\geq 60 \mathrm{~min} /$ week vs none. Combined muscle-strengthening and aerobic activities (vs none) were associated with a $28 \%$ lower total cancer mortality (HR 0.72; 95\% Cl 0.53 to 0.98; $P^{2} 85 \% ; 3$ studies).

Conclusions: Muscle-strengthening activities were associated with reduced incidence of kidney cancer and total cancer mortality. Combined muscle-strengthening and aerobic activities may provide a greater reduction in total cancer mortality.
\end{abstract}

Keywords: Physical activity, Muscle-strengthening activities, Neoplasia, Meta-analysis

\footnotetext{
* Correspondence: leandro.rezende@unifesp.br

'Universidade Federal de São Paulo, Escola Paulista de Medicina,

Departamento de Medicina Preventiva, São Paulo, SP, Brazil

Full list of author information is available at the end of the article
}

C C The Author(s). 2021 Open Access This article is licensed under a Creative Commons Attribution 4.0 International License, which permits use, sharing, adaptation, distribution and reproduction in any medium or format, as long as you give appropriate credit to the original author(s) and the source, provide a link to the Creative Commons licence, and indicate if changes were made. The images or other third party material in this article are included in the article's Creative Commons licence, unless indicated otherwise in a credit line to the material. If material is not included in the article's Creative Commons licence and your intended use is not permitted by statutory regulation or exceeds the permitted use, you will need to obtain permission directly from the copyright holder. To view a copy of this licence, visit http://creativecommons.org/licenses/by/4.0/. The Creative Commons Public Domain Dedication waiver (http://creativecommons.org/publicdomain/zero/1.0/) applies to the data made available in this article, unless otherwise stated in a credit line to the data. 


\section{Introduction}

Physical activity has received much attention in recent years for its potential to prevent some types of cancer [1-3]. In 2018, the World Cancer Research Fund/ American Institute of Cancer Research concluded that convincing evidence exist to support that aerobic, moderate to vigorous physical activity (MVPA) is associated with a reduced risk of colon cancer, and there is probable evidence for a reduction in the risk of breast cancer and endometrial cancer [3]. More recently, the American College of Sports Medicine [1] and the United States Department of Health and Human Services [4] have concluded strong evidence for the relationship between aerobic MVPA and reduced risk of seven types of cancer: breast, colon, endometrial, esophagus, kidney, bladder and stomach. Nevertheless, the potential effect of different types of physical activity for cancer prevention remains unclear [5].

Muscle-strengthening activities are activities that maintain or increase the physical fitness component of muscle strength, as well as body composition, balance and muscular endurance [6]. The 2020 World Health Organization (WHO) physical activity recommendations for health included muscle-strengthening activities involving major muscle groups during at least twice weekly [7], due to their association with a probable reduced risk of cardiovascular mortality [8, 9], type 2 diabetes [10] and all-cause mortality [9]. Yet, the relationship between muscle-strengthening activities and cancer incidence and mortality is uncertain. Recent large prospective cohort studies have reported an association between muscle-strengthening activities with lower total cancer mortality [11], and incidence of colon [12] and kidney cancers [13], but not for other types of cancer [12, 13].

Given these favorable results of muscle-strengthening activities in cancer prevention, we conducted a systematic review to assess the epidemiologic evidence on 1) the association of muscle-strengthening activities with cancer incidence and mortality by types of cancer; 2) the parameters (type, duration, frequency and intensity) of muscle-strengthening activities needed to reduce cancer incidence and mortality; 3) the joint association of muscle-strengthening activities and aerobic MVPA with cancer incidence and mortality; and 4) the association of muscle-strengthening activities with cancer incidence and mortality according to potential effect modifiers.

\section{Methods}

This systematic review was registered under PROSPERO (CRD42020153846) and the reporting followed the PRIS MA 2020 checklist recommendations [14].

\section{Literature search and study selection}

We conducted a broad search, without publication date or language filters, in MEDLINE (via Pubmed), Embase, Web of Science and Scopus databases in March 2020, using search terms related to exposure ("strength training") and outcome ("cancer"). Details on the search strategy can be found in the supplementary material.

Our systematic review aimed to investigate whether muscle-strengthening activities (exposure) can reduce the risk of cancer incidence and mortality (outcome) in participants without cancer at baseline (population). Specifically, our research question addresses primary prevention: Do muscle-strengthening activities prevent cancer incidence and mortality in healthy populations? Observational studies (case-control and cohort) that evaluated the association between muscle-strengthening activities, alone or combined with aerobic MVPA, and cancer incidence or mortality, were eligible for inclusion. The studies should contain information on musclestrengthening activities (e.g., weight training, weightlifting) in healthy adults ( $\geq 18$ years) free of cancer at baseline (for cohort studies). Theoretically, randomized clinical trials were eligible for our analysis, but yielded no results, probably due to logistical and economic issues. Congress abstracts, narrative reviews and cross-sectional studies were ineligible. We excluded cohort studies that included participants with cancer at baseline as they address an entirely different research question - secondary/tertiary prevention: Do muscle-strengthening activities improve cancer survival (reduce total and cancer-specific mortality) in populations with a diagnosis of cancer? Selection of articles first involved reading and evaluating titles and abstracts considering the scope of the systematic review. Then, the full texts were read for the final selection. In both stages, the articles were selected by two researchers (WN and GF) and compared; in cases of disagreement, a third researcher (LFMR) was asked to arbitrate.

\section{Data extraction}

Data were extracted on study characteristics (year of publication and study design), participants (sample size and sociodemographic characteristics), exposure (type, frequency, duration and intensity of the musclestrengthening activities), muscles used, follow-up time (for cohort studies), outcomes (cancer incidence and mortality; types of cancer) and results (e.g., number of cases/deaths, multivariable-adjusted hazard ratios [HR] and $95 \%$ confidence intervals [CI]). When the information was unavailable in the study, we contacted the authors to complement data extraction. 


\section{Risk of bias assessment}

Two researchers (DHL and JPRL) independently assessed the risk of bias in each study using the ROBINS-I tool [15], which included the following bias domains: (1) confounding; (2) bias in the sample selection of the study; (3) bias in the classification of the intervention/exposure; (4) deviations from the intended exposure; (5) bias in the classification of the outcome; (6) bias due to missing data; (7) selection of the reported results. Any disagreement in the assessment was discussed with and resolved by a third researcher (LFMR).

\section{Statistical analysis}

Fixed and random effect meta-analyses were performed to estimate summary measures (HR and 95\% CI) for the association between high vs low levels of musclestrengthening activities and cancer incidence and mortality by types of cancer. "High" was defined as the group with the highest volume (or frequency) of musclestrengthening activities, whereas "low" was the group that reported none or lower volume (or frequency) of muscle-strengthening activities. Subgroup analyses were performed with studies that used similar criteria for categorizing exposure (e.g., $\geq 2$ times/week vs $<2$ times/ week; $\geq 60 \mathrm{~min} /$ week, $1-59 \mathrm{~min} /$ week vs none). Whenever possible, a meta-analysis was conducted to estimate the summary HR and 95\% CI for the joint association of muscle-strengthening activities (e.g., $\geq 2$ times/week vs $<$ 2 times/week; Any vs None) and aerobic MVPA (e.g., $\geq 150$ vs < $150 \mathrm{~min} /$ week) with cancer incidence and mortality. Heterogeneity between study results was quantified by $I^{2}$ and Cochran's Q statistics [16]. The systematic review protocol included assessing small study effects (publication bias) [17] and sources of heterogeneity between studies; but due to the limited number of eligible studies included in the review, these tests were not performed. All statistical analyses were performed using RStudio, version 1.2.5042.

\section{Results}

Search strategy was performed in four databases (MEDL INE [via Pubmed], Embase, Web of Science and Scopus)

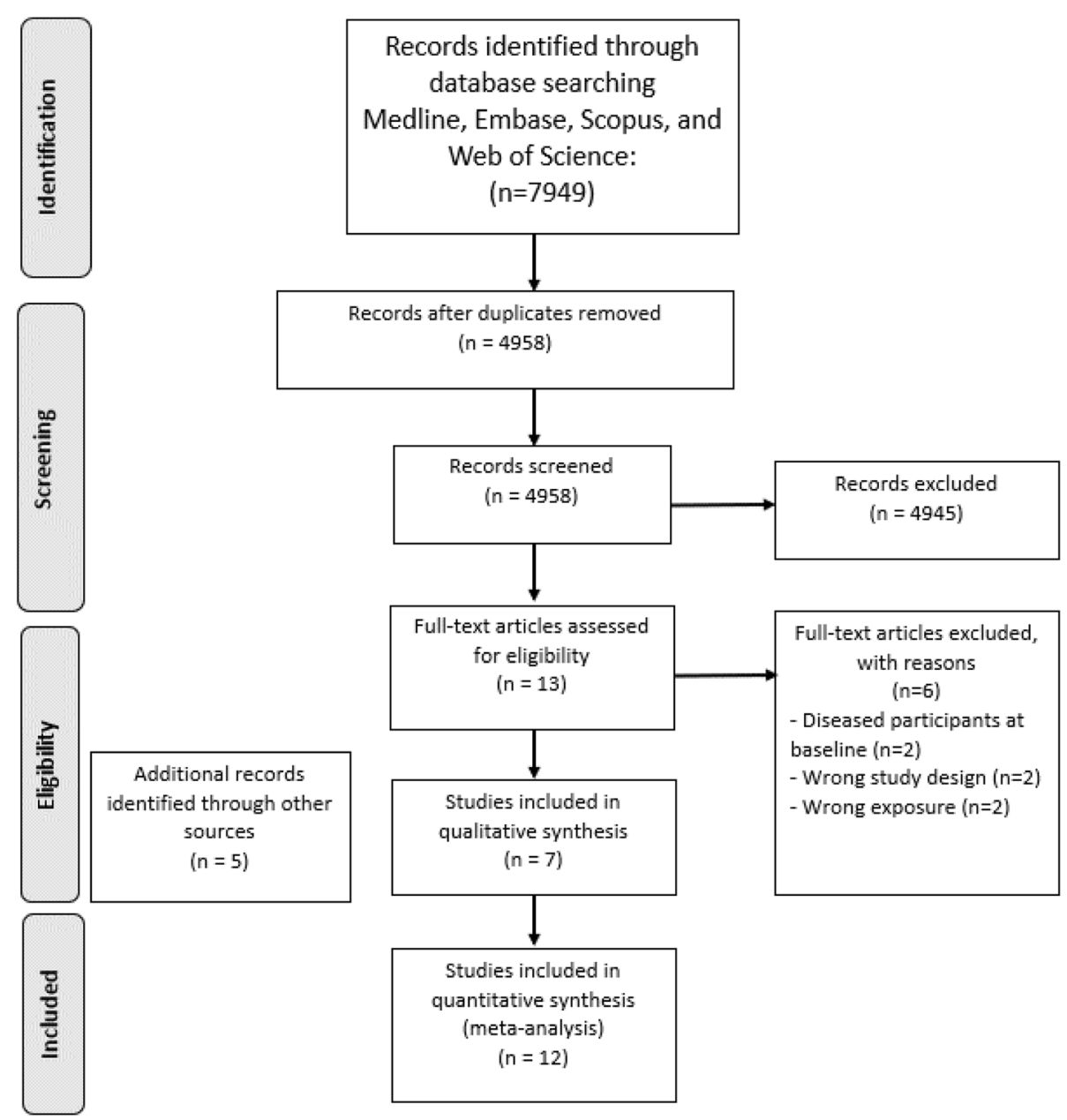

Fig. 1 Preferred Reporting Items for Systematic Reviews and Meta-analysis (PRISMA) flow diagram for search strategy 
and duplicates were removed, obtaining a total of 4958 articles. Of these, 7 met the eligibility criteria for the systematic review. An additional manual search from the lists of recent reviews and included studies, as well as the continuous update from Pubmed alerts yielded 5 eligible studies. Finally, the systematic review included 12 studies [8, 11-13, 18-25] (Fig. 1).

Summarized characteristics of all studies selected in the systematic review are shown in Table S1. Of the 12 articles, eleven were cohort studies $[8,11-13,18-21$, 23-25] and one case-control study [22]; ten studies [8, $12,13,18-21,23-25]$ were conducted in the US, one in Australia [22] and one in the United Kingdom (England and Scotland) [11]. All studies measured musclestrengthening activities via questionnaires. Regarding sample classification, several studies classified participants according to the weekly frequency of musclestrengthening activities [11, 18,20,21, 24, 25], others used weekly duration $[8,12,13,19]$ and equivalent of tasks [22, 23]. A detailed definition of musclestrengthening activities by type of measure, type of activity and analytical categories across the 12 studies is available in Table S1. Regarding the outcomes, eight articles assessed total cancer mortality $[8,11,18-21,24$, $25]$ and four assessed cancer incidence according to primary tumor location, as follows: colon [12, 13, 22], prostate [12, 13], lung [12, 13], kidney [12, 13], lymphoma $[12,13]$, pancreas $[12,13]$, multiple myeloma [13], bladder [12, 13], esophagus [12, 13], rectum [12, 22], melanoma [12], leukemia [13] cancers of the digestive system [23].

Regarding the risk of bias, for the confounding domain, 3 studies were judged as low risk of bias $[8,13$, 23], eight with serious risk of bias [11, 12, 18-21, 24, 25] and one as critical risk of bias [22] (Table 1). For three domains (selection of participants $[8,11-13,19,21,23$, $24]$, classification of the exposures $[8,11-13,18-21,24$, $25]$ and measurement of the outcomes [8, 11-13, 18-21, 23-25]), most of the studies were judged as low risk of bias. For the domain deviations from intended exposures, most of the studies were evaluated as moderate risk of bias [8, 11-13, 18-21, 23-25]. Regarding the missing data domain, four studies were judged as no information $[11,20,24,25]$, three with moderate risk of bias $[12,19,22]$, and five with low risk of bias $[8,13,18$, $21,23]$. For the selection of the reported results domain,

Table 1 Risk of bias judgement by domains of bias using the ROBINS-I tool

\begin{tabular}{|c|c|c|c|c|c|c|c|}
\hline & Confounding $^{a}$ & $\begin{array}{l}\text { Selection of } \\
\text { participants }\end{array}$ & $\begin{array}{l}\text { Classification of } \\
\text { exposure }\end{array}$ & $\begin{array}{l}\text { Deviations from } \\
\text { intended exposures }\end{array}$ & $\begin{array}{l}\text { Missing } \\
\text { data }\end{array}$ & $\begin{array}{l}\text { Measurement of } \\
\text { outcomes }\end{array}$ & $\begin{array}{l}\text { Selection of the } \\
\text { reported result }\end{array}$ \\
\hline $\begin{array}{l}\text { Darkel, } 2016 \\
\text { [25] }\end{array}$ & Serious & Moderate & Low & Moderate & $\mathrm{Ni}$ & Low & Moderate \\
\hline $\begin{array}{l}\text { Boyle, } 2012 \\
{[22]}\end{array}$ & Critical & Serious & Serious & Serious & Moderate & Moderate & Serious \\
\hline $\begin{array}{l}\text { Kamada, } 2017 \\
{[8]}\end{array}$ & Low & Low & Low & Moderate & Low & Low & Moderate \\
\hline $\begin{array}{l}\text { Keum, } 2016 \\
{[23]}\end{array}$ & Low & Low & Moderate & Moderate & Low & Low & Moderate \\
\hline $\begin{array}{l}\text { Kraschnewski, } \\
2016 \text { [18] }\end{array}$ & Serious & Moderate & Low & Moderate & Low & Low & Moderate \\
\hline $\begin{array}{l}\text { Loprinzi, } 2017 \\
\text { [20] }\end{array}$ & Serious & Critical & Low & Moderate & $\mathrm{Ni}$ & Low & Moderate \\
\hline $\begin{array}{l}\text { Mazzilli, } 2019 \\
\text { [12] }\end{array}$ & Serious & Low & Low & Moderate & Moderate & Low & Moderate \\
\hline $\begin{array}{l}\text { Patel, } 2020 \\
\text { [19] }\end{array}$ & Serious & Low & Low & Moderate & Moderate & Low & Moderate \\
\hline $\begin{array}{l}\text { Rezende, } 2020 \\
\text { [13] }\end{array}$ & Low & Low & Low & Moderate & Low & Low & Moderate \\
\hline $\begin{array}{l}\text { Siahpush, } \\
2018 \text { [24] }\end{array}$ & Serious & Low & Low & Moderate & $\mathrm{Ni}$ & Low & Moderate \\
\hline $\begin{array}{l}\text { Stamatakis, } \\
2018[11]\end{array}$ & Serious & Low & Low & Moderate & $\mathrm{Ni}$ & Low & Moderate \\
\hline $\begin{array}{l}\text { Zhao, } 2020 \\
{[21]}\end{array}$ & Serious & Low & Low & Moderate & Low & Low & Moderate \\
\hline
\end{tabular}

a A list of confounders considered in the assessment of risk of confounding: age, sex, smoking, adiposity, alcohol consumption, dietary factors, individual-level socioeconomic factors, and other aerobic physical activities 


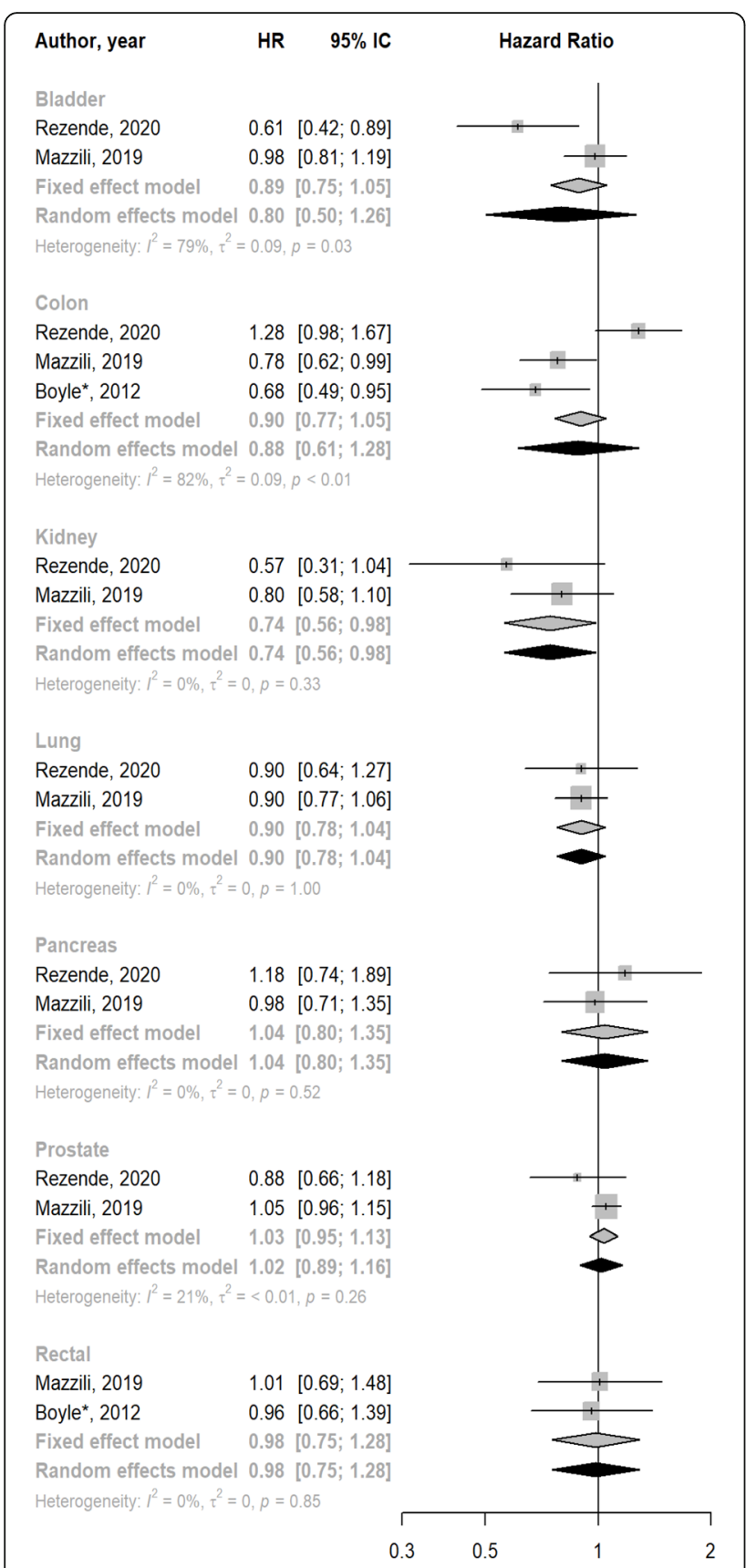

Fig. 2 Meta-analysis for the association between high vs low muscle-strengthening activities and cancer incidence by type of cancer. *Footnote: Case-control study

most of the studies were scored as moderate risk of bias $[8,11-13,18-21,23-25]$ and one as serious risk [22].

\section{Associations of muscle-strengthening activities with cancer incidence and mortality}

Three studies $[12,13,22]$ examined the association between muscle-strengthening activities and incidence of colon cancer, totaling 250,775 participants and 2967 cases. The summary HR for the association between high vs low levels of muscle-strengthening activities and incidence of colon cancer was 0.88 (95\% CI: 0.61 to 1.28; $\mathrm{I}^{2} 82 \%$ ) (Fig. 2).

Rezende et al. [13] and Mazzilli et al. [12] evaluated the association between muscle-strengthening activities and the incidence of ten types of cancer. The summary HR for high vs low levels of muscle-strengthening activities and cancer incidence was 0.80 (95\% CI: 0.50 to 1.26; $I^{2} 79 \%$ ) for bladder cancer, 0.74 (95\% CI: 0.56 to $0.98 ; I^{2} 0 \%$ ) for kidney cancer, 0.90 (95\% CI: 0.78 to 1.04 ; $I^{2} 0 \%$ ) for lung cancer, 1.04 (95\% CI: 0.80 to $1.35 ; I^{2} 0 \%$ ) for pancreatic cancer, and 1.02 (95\% CI: 0.89 to $1.16 ; I^{2}$ 21\%) for prostate cancer (Fig. 2).

Mazzilli et al. [12] and Boyle et al. [22] evaluated the association between muscle-strengthening activities and the incidence of rectal cancer. The summary HR for the association between high vs low levels of musclestrengthening activities and incidence of rectal cancer was 0.98 (95\% CI: 0.75 to $1.28 ; I^{2} 0 \%$ ) (Fig. 2).

Individual studies reported null associations between muscle-strengthening activities and the incidence of lymphoma [13], non-Hodgkin's lymphoma [12, 13], leukemia [13], multiple myeloma [13], melanoma [12] and esophageal cancer [13].

Six studies $[8,11,19,20,24,25]$ were included in the meta-analysis for the association between musclestrengthening activities and total cancer mortality, totaling 493,348 participants and 15,372 deaths. The summary HR for the association between high vs low levels of muscle-strengthening activities and total cancer mortality was 0.87 (95\% CI 0.73 to $1.02 ; I^{2} 58 \%$ ) (Fig. 3A). Four studies [11, 20, 24, 25] used the criterion $\geq 2$ times/ week vs $<2$ times/week of muscle-strengthening activities, with a summary HR for total cancer mortality of 0.81 (95\% CI 0.74 to $0.87 ; \mathrm{I}^{2}$ 0\%) (Fig. 3B). Two studies $[8,19]$ assessed the weekly duration of musclestrengthening activities. Compared with participants who performed no muscle-strengthening activities, the summary HR for total cancer mortality was 0.91 (95\% CI 0.82 to $\left.1.01 ; I^{2} 0 \%\right)$ for $1-59 \mathrm{~min} /$ week and $0.98(95 \%$ CI 0.89 to $1.07 ; I^{2} 0 \%$ ) for $\geq 60 \mathrm{~min} /$ week (Fig. $3 \mathrm{C}$ ).

\section{Joint association of muscle-strengthening and aerobic activities with cancer incidence and mortality}

Two studies [12,13] assessed the joint association of muscle-strengthening activities and aerobic MVPA with colon cancer incidence, totaling 248,909 participants and 2415 cases. Compared with participants that performed neither muscle-strengthening activities nor aerobic MVPA, the summary HR for colon cancer incidence was 0.80 (95\% CI 0.62 to $\left.1.03 ; I^{2} \quad 0 \%\right)$ for musclestrengthening activities only, 0.92 (95\% CI 0.84 to 1.01; $I^{2} 0 \%$ ) for aerobic MVPA only, and 0.80 (95\% CI 0.59 to 
(A) high vs low muscle-strengthening activities and total cancer mortality

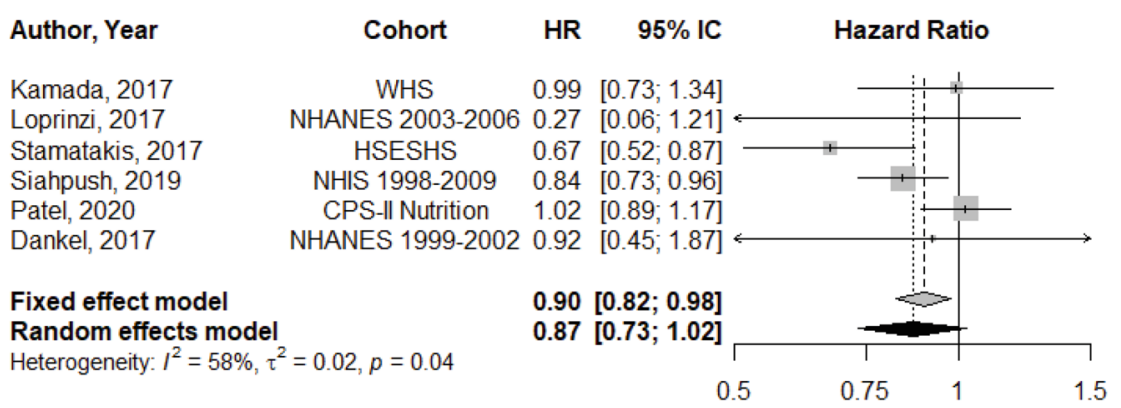

(B) $\geq 2$ times/week vs $<2$ times/week of muscle-strengthening activities and total cancer mortality

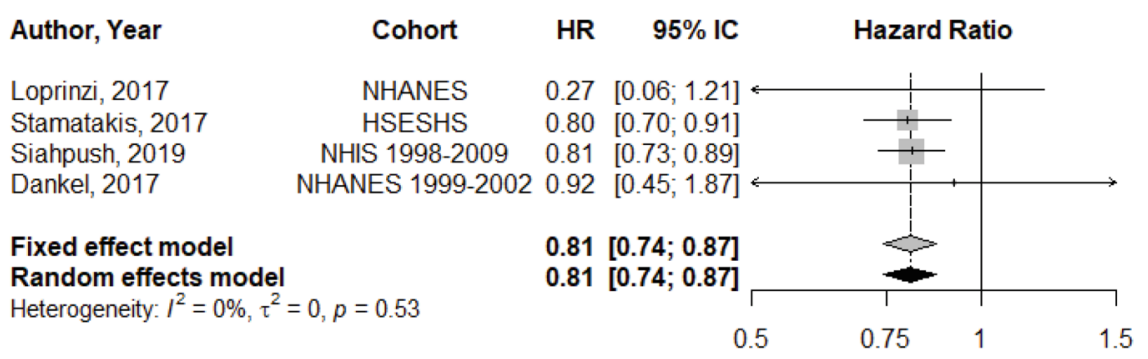

(C) Duration of muscle-strengthening activities and total cancer mortality

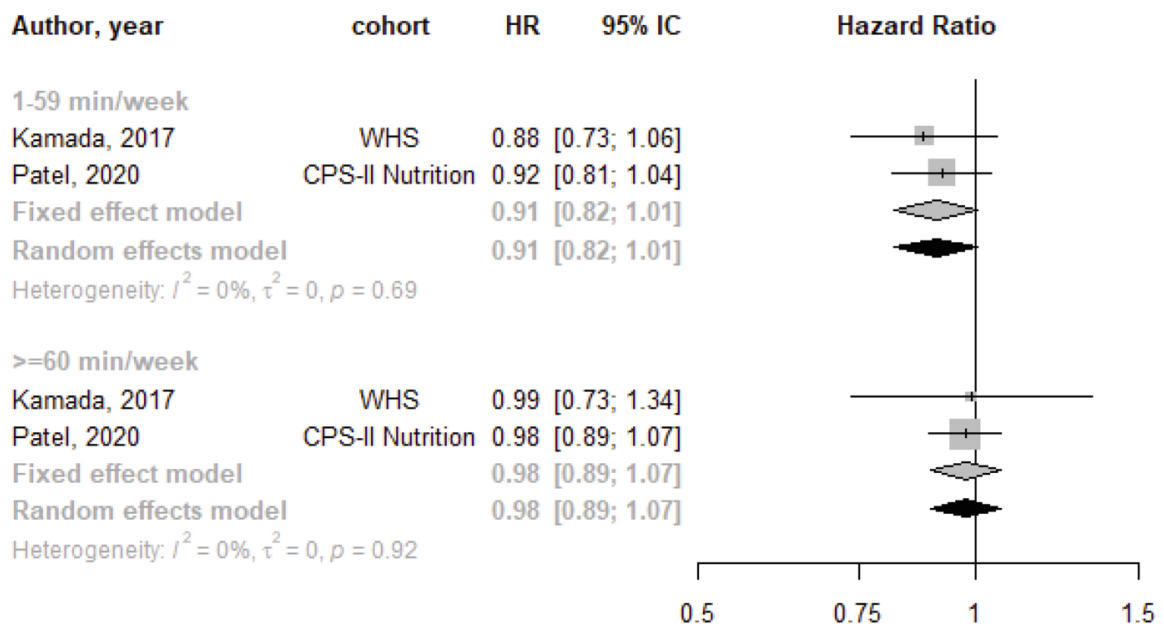

Fig. 3 Meta-analysis for the association between $\mathbf{A}$ high vs low; B weekly frequency; and $\mathbf{C}$ duration of muscle-strengthening activities and total cancer mortality

1.09; $I^{2}$ 83\%) for muscle-strengthening activities plus aerobic MVPA (Fig. 4; Figure S1).

Individual studies found that combined musclestrengthening activities and aerobic MVPA (vs none) was associated with a lower incidence of kidney [13] and bladder [13] cancers, but not with cancers of the digestive system [23].

Three studies $[8,11,21]$ examined the joint association of muscle-strengthening activities and aerobic
MVPA with total cancer mortality, with a total of 585,930 participants and 17,212 cancer deaths. Compared with participants who performed neither muscle-strengthening activities nor aerobic MVPA, the summary $\mathrm{HR}$ for total cancer mortality was 0.83 (95\% CI 0.73 to $0.94 ; I^{2} 21 \%$ ) for musclestrengthening activities only, 0.89 (95\% CI 0.72 to $\left.1.10 ; I^{2} 90 \%\right)$ for aerobic MVPA only, and 0.72 (95\% CI 0.53 to $\left.0.98 ; I^{2} \quad 85 \%\right)$ for muscle- 


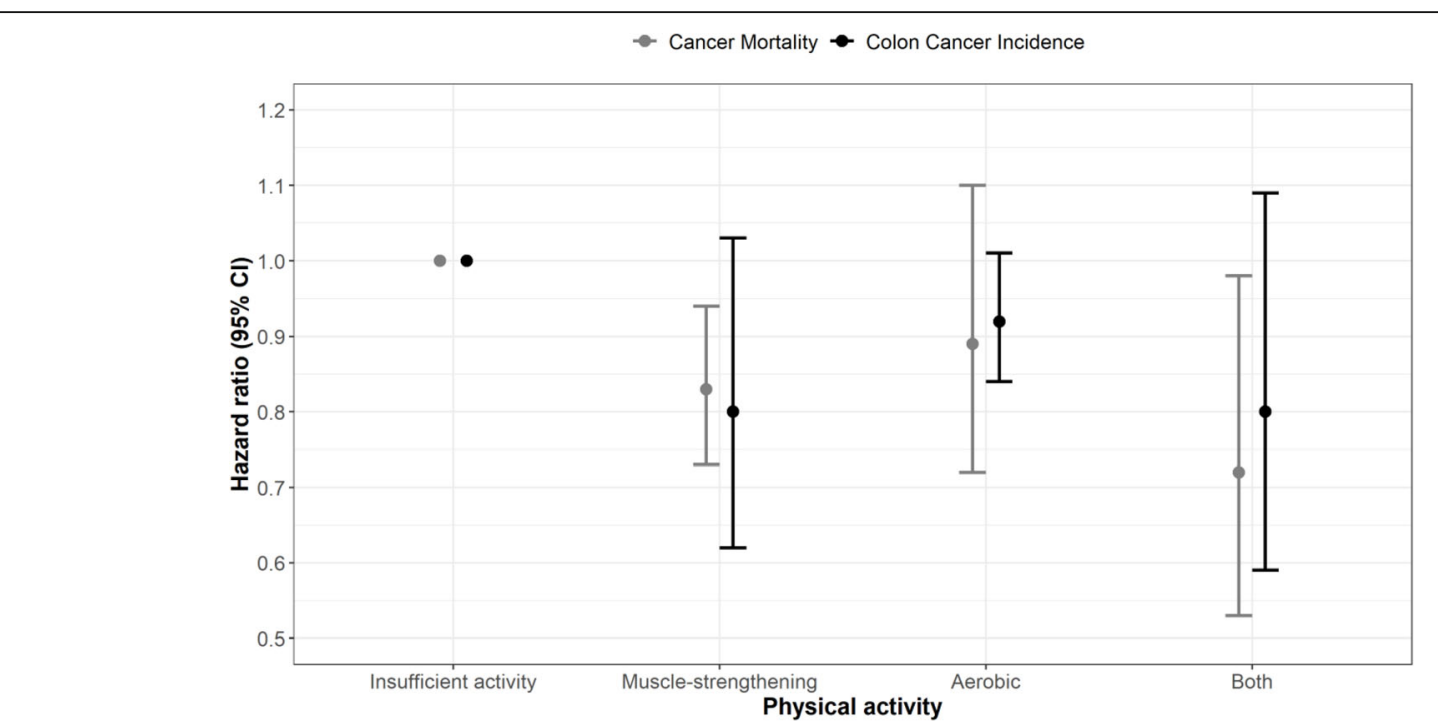

Fig. 4 Meta-analysis for the joint association of muscle-strengthening and aerobic activities with colon cancer incidence and total cancer mortality. Footnote: Three studies performed joint association of muscle-strengthening activities and aerobic MVPA with colon cancer incidence and total cancer mortality. The muscle-strengthening and aerobic activity groups were defined as follow: Total Cancer Mortality: Kamada et al: Insufficient activity (Reference): < $150 \mathrm{~min} /$ week of aerobic MVPA and no strength training; Aerobic activities only: Aerobic MVPA $\geq 150 \mathrm{~min} /$ week and no strength training; Muscle-strengthening activities only: < $150 \mathrm{~min} /$ week of aerobic MVPA and any strength training; Both: Aerobic MVPA $\geq 150 \mathrm{~min} /$ week and any strength training; Stamatakis et al: Insufficient activity (Reference): $<150 \mathrm{~min} /$ week of aerobic MVPA and $<2$ times/week of strength training; Aerobic activities only: Aerobic MVPA $\geq 150 \mathrm{~min} /$ week and $<2$ times/week of strength training; Muscle-strengthening activities only: $<150 \mathrm{~min} /$ week of aerobic MVPA and $\geq 2$ times/week of strength training; Both: Aerobic MVPA $\geq 150 \mathrm{~min} /$ week and $\geq 2$ times/ week of strength training.; Zhao et al.: Insufficient activity (Reference): $<150 \mathrm{~min}$ of light to moderate intensity activity each week, or $<75$ min of vigorous intensity activity, or less than an equivalent combination and $<2$ times/week of muscle-strengthening activities; Aerobic activities only: $\geq 150 \mathrm{~min}$ of light to moderate intensity activity each week, or $\geq 75 \mathrm{~min}$ of vigorous intensity activity, or greater than or equal to an equivalent combination and $<2$ times/week of muscle-strengthening activities; Muscle-strengthening activities only: $<150$ min of light to moderate intensity activity each week, or $<75$ min of vigorous intensity activity, or less than an equivalent combination and $\geq 2$ times/week of muscle-strengthening activities; Both: $\geq 150 \mathrm{~min}$ of light to moderate intensity activity each week, or $\geq 75 \mathrm{~min}$ of vigorous intensity activity, or greater than or equal to an equivalent combination and $\geq 2$ times/week of muscle-strengthening activities. Colon cancer incidence: Rezende et al: Insufficient activity (Reference): $<16$ MET-h/week of aerobic MVPA and no resistance training; Aerobic activities only: $\geq 16$ MET-h/week of aerobic MVPA and no resistance training; Muscle-strengthening activities only: < 16 MET-h/week of aerobic MVPA and any resistance training; Both: $\geq 16$ MET-h/week of aerobic MVPA and any resistance training. Mazzilli et al: Insufficient activity (Reference): $<7.5 \mathrm{MET}$-h/week of aerobic MVPA and no weight lifting; Aerobic activities only: $\geq 7.5$ MET-h/week of aerobic MVPA and no resistance tr no weight lifting; Muscle-strengthening activities only: $<7.5$-h/ week of aerobic MVPA and any weight lifting; Both: $\geq 7.5 \mathrm{MET}-\mathrm{h} /$ week of aerobic MVPA and any weight lifting

strengthening activities plus aerobic MVPA (Fig. 4; Figure S2).

\section{Discussion}

Our systematic review suggested that musclestrengthening activities were associated with lower incidence of kidney cancer. Pooled results from two large prospective cohort studies $[12,13]$ suggested that muscle-strengthening activities were associated with a $26 \%$ lower incidence of kidney cancer when comparing high vs low levels of muscle-strengthening activities. Results for the other 12 types of cancer included in our systematic review were inconclusive due to limited number of studies. For instance, among the same aforementioned cohort studies [12, 13] that evaluated the association between muscle-strengthening activities and incidence of colon cancer, Mazzilli et al. [12] found an inverse association with muscle-strengthening activities, whereas Rezende et al. [13], found a positive association. Of note, this positive association was restricted to the subgroup of ever smokers and participants with overweight/obesity. In addition, joint analysis between muscle-strengthening activities and aerobic MVPA suggested a null association with colon cancer [13].

We found that muscle-strengthening activities were associated with a $13 \%$ lower total cancer mortality and that joint muscle-strengthening activities and aerobic MVPA with a $28 \%$ lower total cancer mortality. A previous meta-analysis found that muscle-strengthening activities were also associated with lower all-cause and cardiovascular disease mortality [9]. The amount of muscle-strengthening activities required to achieve optimum cancer prevention remains, however, unclear. Four studies [11, 20, 24, 25] that categorized the frequency of muscle-strengthening activities as $\geq 2$ times/ week (vs $<2$ times/week) found a 19\% lower total cancer 
mortality. Two studies $[8,19]$ observed that, as compared with participants who performed no musclestrengthening activities, those practicing 1-59 $\mathrm{min} /$ week had a $9 \%$ non-statistically significant lower cancer mortality. Nevertheless, there was a null association with total cancer mortality in participants doing $\geq 60 \mathrm{~min} /$ week of muscle-strengthening activities vs none, possibly due to limited number of events when considering this contrast.

Deciphering the causal contribution of a specific type of physical activity on cancer prevention is challenging. Low within-population variability and measurement error for physical activity are important concerns [26, 27]. Future prospective cohort studies with objective measures of physical activity may reduce misclassification and, consequently, reduce current uncertain evidence. That being said, the current technology of accelerometers cannot accurately capture the musclestrengthening activities for scientific research purposes. Thus, a combination of questionnaires, diaries and heart rate monitoring will likely be more useful to reduce measurement error. In the meantime, results from large pooled consortia using questionnaires [28] may boost the current scientific evidence, particularly for less common cancers.

The biological mechanisms whereby musclestrengthening activities prevent cancer are not yet fully explained, but a few hypotheses have been proposed. Some of these hypotheses may not be limited to musclestrengthening activities, and would encompass other types of exercise and aerobic activities. The first relates to the direct benefits of muscle-strengthening activities on body composition, as a high level of body fat is directly related to the incidence of cancer. These same biological mechanisms have also been postulated for the association between aerobic MVPA and cancer incidence [29]. Excess adiposity causes insulin resistance, which in turn leads to an elevated levels of bioactive insulin-like growth factor-1 (IGF-1); both insulin and IGF-1 can increase proliferation and reduce apoptosis in sensitive cells [30]. Obesity is often accompanied by unfavorable changes to the intestinal microbiota, increasing the production of pro-inflammatory factors and some hormones, such estrogen, an important factor for breast cancer [30, 31]. Of note, most studies included in our systematic review adjusted for BMI in the multivariable models, which may have attenuated the magnitude of the associations.

A second hypothesis is that muscle-strengthening activities enhance muscle mass, which in turn enhances glucose control [10, 32]. High intensity strength training may also lead to a specific increase in free radicals, which could trigger adaptations in the body by generating more antioxidants, and may have an impact on epigenetic factors, such as DNA methylation [32, 33]. Additionally, enhanced muscle mass improves immunity, with some studies showing an improvement in natural killer cell activity, which could bolster anti-tumor reaction [32, 33]. Finally, physical activity improves microcirculation thus reducing hypoxic environments, which are important for tumor development: in their presence, tumor cells increase the expression of vascular endothelial growth factor, consequently, increasing the vascularization of the neoplastic masses [32, 34]. Of note, because most of these biological pathways are related to overall physical activity, future mechanistic studies may uncover causal links between musclestrengthening activities and cancer incidence and mortality.

Our systematic review has some limitations that warrant consideration. First, results from meta-analyses are prone to measurement errors inherent in the included studies. Measurement error in muscle-strengthening activities could have affected the magnitude of the associations. In this case, as most of the studies included in our systematic review were prospective cohort studies, we expect that measurement error of muscle-strengthening activities being non-differential in regard to the outcome ascertained; thus, non-differential measurement error of the exposure may have underestimated the magnitude of the associations of high versus low levels of musclestrengthening activities with cancer incidence and mortality. All studies included in our systematic review were based on participants' self-report, so the actual intensity or duration of the muscle-strengthening activities performed cannot be established. Second, the studies reviewed used different questions to assess participation in muscle-strengthening activities and different analytical categories. This may have increased the statistical heterogeneity between studies, e.g., moderate to high in the meta-analysis for total cancer mortality ( $\left.I^{2} 58 \%\right)$; thus, we have summarized the results across studies using random-effect model, which provides a wider confidence interval of the summary HR and more conservative claims of statistical significance compared to fixed-effect models. We could not explore the sources of heterogeneity between studies due to limited number of studies. Third, studies were conducted in US, Australia and United Kingdom, while limiting generalizability, particularly to low- and middleincome countries. Finally, our risk of bias assessment suggests that most of the studies are prone to bias, particularly confounding bias and selective reporting bias. For instance, most studies did not adjust for dietary factors (e.g., red and processed meat) that may play a role in cancer incidence and mortality. Residual confounding by smoking is also a concern in physical activity and cancer studies [26, 28]. Selective 
reporting of a particular outcome, analysis or subset of participants may lead to bias if based on direction, magnitude of the association or statistical significance of results [15]. All studies included in our review did not provide an analysis specified in a protocol or statistical analysis plan, before analyses were carried out, to be graded as low risk of bias. Future studies should embrace reproducible research practices (e.g., protocol registration) to reduce reporting bias.

\section{Conclusion}

In conclusion, our systematic literature review suggests that muscle-strengthening activities might play a preventive role for incidence of kidney cancer. In addition, we found that muscle-strengthening activities might be a protective factor for total cancer mortality, and that performing both muscle-strengthening and aerobic activities may provide a larger reduction in total cancer mortality. The associations between musclestrengthening and incidence of other types of cancer remain inconclusive due to the limited number of studies and moderate to high heterogeneity between results. Future prospective cohort studies with long-term followup, repeated-measures of muscle-strengthening activities over time and the intensity they are performed, and detailed covariates including aerobic MVPA should be conducted to provide a stronger evidence-base for synthesis. In addition, studies including more diverse populations with wide range of muscle-strengthening activities are needed to increase generalizability and to define dose-response relationship of musclestrengthening activities with cancer incidence and mortality.

\section{Abbreviations}

Cls: Confidence intervals; HR: Hazard ratio; MVPA: Moderate to vigorous physical activity; WHO: World Health Organization

\section{Supplementary Information}

The online version contains supplementary material available at https://doi. org/10.1186/s12966-021-01142-7.

Additional file 1.

\section{Acknowledgements}

None.

\section{Authors' contributions}

L.F.M.R. had full access to all of the data in the study and takes responsibility for the integrity of the data and the accuracy of the data analysis. Concept and design: L.F.M.R., W.N. Acquisition, analysis, or interpretation of data: L.F.M.R., C.B.M., W.N. Drafting of the manuscript: W.N. and L.F.M.R. Critical revision of the manuscript for important intellectual content: D.H.L., G.F, J.P.R.L., M.I., E.G., C.B.M. Statistical analysis: C.B.M, Administrative, technical, or material support: G.F. All authors have read and agree to publish the final manuscript.

\section{Funding}

This work was supported by Sao Paulo Research Foundation (FAPESP), grant 2019/26326-6 (W.N. Scientific Initiation fellowship). This study was financed in part by the Coordenação de Aperfeiçoamento de Pessoal de Nível Superior - Brasil (CAPES) - Finance Code 001. The funding body had no involvement in design of the study, data collection, analysis, interpretation of data or in the drafting of the manuscript.

\section{Availability of data and materials}

All data generated as part of this systematic review are included as additional files in this published article.

\section{Declarations}

Ethics approval and consent to participate Not applicable.

\section{Consent for publication}

Not applicable.

\section{Competing interests}

All authors declare that they have no competing interests.

\section{Author details}

${ }^{1}$ Universidade Federal de São Paulo, Escola Paulista de Medicina, Departamento de Medicina Preventiva, São Paulo, SP, Brazil. ${ }^{2}$ Universidad de Santiago de Chile (USACH), Escuela de Ciencias de la Actividad Física, el Deporte y la Salud, Santiago, Chile. ${ }^{3}$ Faculty of Health Sciences, International University of Valencia (VIU), Valencia, Spain. ${ }^{4}$ Faculty of Sport, Catholic University San Antonio of Murcia, Murcia, Spain. ${ }^{5}$ Navarrabiomed, Navarra Hospital Complex (NHC), Universidad Pública de Navarra (UPNA), IdiSNA, Pamplona, Spain. ${ }^{6}$ Department of Nutrition, Harvard T.H. Chan School of Public Health, Boston, MA, USA. ${ }^{7}$ Department of Epidemiology, Harvard T.H. Chan School of Public Health, Boston, MA, USA. ${ }^{8}$ Channing Division of Network Medicine, Department of Medicine, Brigham and Women's Hospital and Harvard Medical School, Boston, MA, USA.

Received: 19 February 2021 Accepted: 20 May 2021

Published online: 29 May 2021

\section{References}

1. Patel AV, Friedenreich CM, Moore SC, Hayes SC, Silver JK, Campbell KL, et al. American College of Sports Medicine roundtable report on physical activity, sedentary behavior, and Cancer prevention and control. Med Sci Sports Exerc. 2019;51(11):2391-402. https://doi.org/10.1249/MSS.0000000000002117.

2. Rock CL, Thomson C, Gansler T, Gapstur SM, McCullough ML, Patel AV, et al. American Cancer Society guideline for diet and physical activity for cancer prevention. CA Cancer J Clin. 2020;70(4):245-71. https://doi.org/10.3322/caa c.21591.

3. World Cancer Research Fund/American Institute for Cancer Research. Continuous Update Project Expert Report 2018. Physical activity and the risk of cancer. Available at: dietandcancerreport.org.

4. McTiernan A, Friedenreich CM, Katzmarzyk PT, Powell KE, Macko R, Buchner $D$, et al. Physical activity in Cancer prevention and survival: a systematic review. Med Sci Sports Exerc. 2019;51(6):1252-61. https://doi.org/10.1249/ MSS.0000000000001937.

5. Mahabir S, Willett WC, Friedenreich CM, Lai GY, Boushey CJ, Matthews CE, et al. Research strategies for nutritional and physical activity epidemiology and Cancer prevention. Cancer Epidemiol Biomark Prev. 2018;27(3):233-44. https://doi.org/10.1158/1055-9965.EPI-17-0509.

6. Bennie JA, Shakespear-Druery J, De Cocker K. Muscle-strengthening exercise epidemiology: a new frontier in chronic disease prevention. Sports Med Open. 2020;6(1):40. https://doi.org/10.1186/s40798-020-00271-w.

7. Bull FC, Al-Ansari SS, Biddle S, Borodulin K, Buman MP, Cardon G, et al. World Health Organization 2020 guidelines on physical activity and sedentary behaviour. Br J Sports Med. 2020;54(24):1451-62. https://doi.org/1 0.1136/bjsports-2020-102955.

8. Kamada M, Shiroma EJ, Buring JE, Miyachi M, Lee IM. Strength Training and All-Cause, Cardiovascular Disease, and Cancer Mortality in Older Women: A Cohort Study. J Am Heart Assoc. 2017;6(11):e007677. 
9. Saeidifard F, Medina-Inojosa JR, West CP, Olson TP, Somers VK, Bonikowske $A R$, et al. The association of resistance training with mortality: a systematic review and meta-analysis. Eur J Prev Cardiol. 2019;26(15):1647-65. https:// doi.org/10.1177/2047487319850718.

10. Grontved A, Rimm EB, Willett WC, Andersen LB, Hu FB. A prospective study of weight training and risk of type 2 diabetes mellitus in men. Arch Intern Med. 2012;172(17):1306-12. https://doi.org/10.1001/archinternmed.2012.313 8.

11. Stamatakis E, Lee IM, Bennie J, Freeston J, Hamer M, O'Donovan G, et al. Does strength-promoting exercise confer unique health benefits? A pooled analysis of data on 11 population cohorts with all-cause, Cancer, and cardiovascular mortality endpoints. Am J Epidemiol. 2018;187(5):1102-12. https://doi.org/10.1093/aje/kwx345.

12. Mazzilli KM, Matthews CE, Salerno EA, Moore SC. Weight training and risk of 10 common types of Cancer. Med Sci Sports Exerc. 2019;51(9):1845-51. https://doi.org/10.1249/MSS.0000000000001987.

13. Rezende LFM, Lee DH, Keum N, Wu K, Eluf-Neto J, Tabung FK, et al. Resistance training and total and site-specific cancer risk: a prospective cohort study of 33,787 US men. Br J Cancer. 2020;123(4):666-72. https://doi. org/10.1038/s41416-020-0921-8

14. Page MJ, McKenzie JE, Bossuyt PM, Boutron I, Hoffmann TC, Mulrow CD, et al. The PRISMA 2020 statement: an updated guideline for reporting systematic reviews. BMJ. 2021;372:n71.

15. Sterne JA, Hernan MA, Reeves BC, Savovic J, Berkman ND, Viswanathan M, et al. ROBINS-I: a tool for assessing risk of bias in non-randomised studies of interventions. BMJ. 2016:355:i4919.

16. Ioannidis JP, Patsopoulos NA, Evangelou E. Uncertainty in heterogeneity estimates in meta-analyses. BMJ. 2007;335(7626):914-6. https://doi.org/1 0.1136/bmj.39343.408449.80.

17. Egger M, Davey Smith G, Schneider M, Minder C. Bias in meta-analysis detected by a simple, graphical test. BMJ. 1997;315(7109):629-34. https:// doi.org/10.1136/bmj.315.7109.629.

18. Kraschnewski JL, Sciamanna CN, Poger JM, Rovniak LS, Lehman EB, Coope $A B$, et al. Is strength training associated with mortality benefits? A 15year cohort study of US older adults. Prev Med. 2016;87:121-7. https://doi.org/1 0.1016/j.ypmed.2016.02.038.

19. Patel AV, Hodge JM, Rees-Punia E, Teras LR, Campbell PT, Gapstur SM. Relationship between muscle-strengthening activity and causespecific mortality in a large US cohort. Prev Chronic Dis. 2020;17: E78.

20. Loprinzi PD, Addoh O, Mann JR. Association between muscle strengthening physical activities and mortality among American adults with mobility limitations. Prev Med. 2017;99:207-10. https://doi.org/10.1016/j.ypmed.2017. 02.013.

21. Zhao M, Veeranki SP, Magnussen CG, Xi B. Recommended physical activity and all cause and cause specific mortality in US adults: prospective cohort study. BMJ. 2020;370:m2031.

22. Boyle T, Bull F, Fritschi L, Heyworth J. Resistance training and the risk of colon and rectal cancers. Cancer Causes Control. 2012;23(7):1091-7. https:// doi.org/10.1007/s10552-012-9978-X.

23. Keum N, Bao Y, Smith-Warner SA, Orav J, Wu K, Fuchs CS, et al. Association of Physical Activity by type and intensity with digestive system Cancer risk. JAMA Oncol. 2016;2(9):1146-53. https://doi.org/10.1001/jamaoncol.2016.074 0.

24. Siahpush M, Farazi PA, Wang H, Robbins RE, Singh GK, Su D. Musclestrengthening physical activity is associated with cancer mortality: results from the 1998-2011 National Health Interview Surveys, National Death Index record linkage. Cancer Causes Control. 2019;30(6):663-70. https://doi.org/1 0.1007/s10552-019-01169-z

25. Dankel SJ, Loenneke JP, Loprinzi PD. Cancer-specific mortality relative to engagement in muscle-strengthening activities and lower extremity strength. J Phys Act Health. 2018;15(2):144-9. https://doi.org/10.1123/jpah.2 016-0204.

26. Giovannucci E. An integrative approach for deciphering the causal associations of physical activity and Cancer risk: the role of adiposity. J Natl Cancer Inst. 2018;1 10(9):935-41. https://doi.org/10.1093/jnci/djy091.

27. Lee DH, Rezende LFM, Ferrari G, Aune D, Keum N, Tabung FK, et al. Physical activity and all-cause and cause-specific mortality: assessing the impact of reverse causation and measurement error in two large prospective cohorts. Eur J Epidemiol. 2021;36(3):275-85. https://doi.org/10.1007/s10654-02000707-3.
28. Moore SC, Lee IM, Weiderpass E, Campbell PT, Sampson JN, Kitahara CM, et al. Association of Leisure-Time Physical Activity with Risk of 26 types of Cancer in 1.44 million adults. JAMA Intern Med. 2016;176(6):816-25. https:// doi.org/10.1001/jamainternmed.2016.1548.

29. Lauby-Secretan B, Scoccianti C, Loomis D, Grosse Y, Bianchini F, Straif K, et al. Body fatness and Cancer--viewpoint of the IARC working group. $N$ Engl J Med. 2016;375(8):794-8. https://doi.org/10.1056/NEJMsr1606602.

30. O'Flanagan $\mathrm{CH}$, Bower LW, Allott EH, Hursting SD. Hursting, molecular and metabolic mechanisms underlying the obesity-cancer link. In: Romieu I, Dossus L, Willett W, editors. Energy balancer and obesity (IARC working group reports 10). Lyon: International Agency for Research on Cancer; 2017.

31. Lee DH, de Rezende LFM, Eluf-Neto J, Wu K, Tabung FK, Giovannucci EL. Association of type and intensity of physical activity with plasma biomarkers of inflammation and insulin response. Int J Cancer. 2019;145(2):360-9. https://doi.org/10.1002/ijc.32111.

32. Friedenreich CM, Ryder-Burbidge C, McNeil J. Physical activity, obesity and sedentary behavior in cancer etiology: epidemiologic evidence and biologic mechanisms. Mol Oncol. 2021;15(3):790-800. https://doi.org/10.1002/18780261.12772.

33. McTiernan A. Mechanisms linking physical activity with cancer. Nat Rev Cancer. 2008:8(3):205-11. https://doi.org/10.1038/nrc2325.

34. Wang Q, Zhou W. Roles and molecular mechanisms of physical exercise in cancer prevention and treatment. J Sport Health Sci. 2021;10(2):201-10. https://doi.org/10.1016/j.jshs.2020.07.008.

\section{Publisher's Note}

Springer Nature remains neutral with regard to jurisdictional claims in published maps and institutional affiliations.
Ready to submit your research? Choose BMC and benefit from:

- fast, convenient online submission

- thorough peer review by experienced researchers in your field

- rapid publication on acceptance

- support for research data, including large and complex data types

- gold Open Access which fosters wider collaboration and increased citations

- maximum visibility for your research: over $100 \mathrm{M}$ website views per year

At $\mathrm{BMC}$, research is always in progress.

Learn more biomedcentral.com/submissions 